\title{
Project Crashing with Crash Duration Consumption Rate: An Illustrative Example
}

\author{
Harun Turkoglu' ${ }^{1}$ Gul Polat ${ }^{2}$, Atilla Damci ${ }^{3}$ and Firat Dogu Akin ${ }^{4}$
}

1 Istanbul Technical University, Istanbul, Turkey, hturkoglu@itu.edu.tr

2 Istanbul Technical University, Istanbul, Turkey, polatgu@itu.edu.tr

3 Istanbul Technical University, Istanbul, Turkey, damcia@itu.edu.tr

4 Istanbul Technical University, Istanbul, Turkey, akinf@itu.edu.tr

\begin{abstract}
Completing on time, within the estimated budget and at the desired quality are three main constraints of construction projects. However, construction projects become nowadays more complex than ever, so they are subjected to uncertainties and changes throughout the project life cycles. These uncertainties and changes may lead to severe delays in project duration. Therefore, project managers desire to reduce the project duration without changing scope of the project. Crashing a project is an advanced project management strategy, which aims to achieve the maximum reduction in project duration with the minimum additional cost without changing the scope. However, project crashing is a difficult task and should be used if it is necessarily needed. This paper proposes a model that considers crash duration consumption rates of activities for solving the project crashing problem. The crash duration consumption rate is the percentage that is set to determine the maximum amount of crash duration that an activity can consume with safety margin. The proposed model enables the schedulers to assign crash duration consumption rates to each activity that can be used during the project crashing procedure. Having applied the proposed model, the Monte Carlo simulation is also performed to determine the probability of completion of the project at the latest in crashed project duration. The applicability of the proposed model is presented along with an illustrative example. The proposed model is supposed to minimize the likelihood of delays, while maintaining schedule flexibility. In addition, the proposed model provides schedulers a new perspective in solving project crashing problems.
\end{abstract}

(c) 2020 The Authors. Published by Budapest University of Technology and Economics \& Diamond Congress Ltd Peer-review under responsibility of the Scientific Committee of the Creative Construction Conference 2020.

Keywords: crash duration consumption rate, illustrative example, Monte Carlo simulation, project crashing

\section{Introduction}

Delays are one of the most serious and common problems in construction projects [1]. Delays not only affect the project duration, but also increase the total cost of the project and reduce the project quality [2]. In general, the performance of a construction project is measured by three main constraints; the completion of that project on time, within the estimated budget and at the desired quality [3]. In order to decrease or eliminate the delays that have a negative impact on the project performance [4], project managers desire to reduce the project duration without changing scope of the project to meet the specified project deadline [5]. One of the effective ways to reduce the project duration is the project crashing [6]. The duration of a project can be shortened by accelerating the normal critical activities' durations with minimum additional cost by allocating more or efficient resources (labor, equipment or materials), working multiple shifts, and extending working days [7-12]. Implementation of these strategies increases the direct costs associated with such activities, but also decreases total indirect costs by reducing the project duration [7]. Therefore, project crashing has a direct impact on two of the project's three main constraints, which are 
time and cost. As a result, the project crashing problem can be defined as 'the time-cost trade-off problem, which aims to achieve the maximum reduction in project duration with the minimum additional cost without changing the scope' [13].

The reduction of project duration has always been a difficult task for project managers, so a number of researchers have developed different mathematical models, heuristic and meta-heuristic algorithms to solve the time-cost trade-off problem for years [9]. In addition, the time-cost trade-off problem has been extensively studied in the literature since the problem was first mathematically formulated by Kelly and Walker in $1957[14,15]$. Although the reduction of project duration day by day causes a decrease in the floats of non-critical activities, resulting in an increased risk of not the completion of project on time [16], most of the previous studies focusing on project crashing do not address maintaining schedule flexibility. Few studies (e.g., Rabie and El-Sayegh, 2017 [16]; El-Sayegh and Al-Haj, 2017 [17]) have evaluated float loss as cost to provide schedule flexibility in time-cost trade-off problems. In time-cost trade-off problems, there is still a need for developing more efficient models that will provide schedule flexibility while project duration is reduced. Therefore, the main objective of the study to fill this gap. The proposed crashing model aims to provide a flexibility for the normal critical activities to be re-crashed if necessary during execution phase of the project. This paper proposes a model that considers crash duration consumption rates of activities for solving the project crashing problem. In order to demonstrate how the proposed model can be applied in a real life project, an illustrative example was also performed.

\section{The proposed project crashing model}

The proposed model was developed through Visual Basic Programming Language integrated with Microsoft (MS) Excel. An Excel-based model was preferred because it is reliable and transparent through easy observation of the program's performance at every stage of the process. The proposed model mainly consists of seven main steps, which are briefly explained below:

Step 1: In this step, the necessary inputs for the developed model are determined. The inputs of the proposed model and their notations are presented in Table 1.

Table 1. The inputs of the proposed model and their notations.

\begin{tabular}{ll}
\hline Notation & Definition \\
\hline$i$ & Predecessor of activity $j$ \\
$j$ & Successor of activity $i$ \\
$N$ & Total number of activities in the project \\
$t_{i}$ & Normal duration of activity $i$ \\
$m c t_{i}$ & Maximum crash duration of activity $i$ \\
$c r_{i}$ & Crash duration consumption rate of activity $i$ (between 0 and 1 ) \\
$a c t_{i}$ & Allowable crash duration of activity $i$ \\
$n c_{i}$ & Normal (direct) cost of activity $i$ \\
$d n c_{i}$ & Daily normal cost of activity $i$ \\
$c c_{i}$ & Daily crashing cost of activity $i$ \\
$i c_{p}$ & Daily indirect cost of the project \\
\hline
\end{tabular}

Step 2: In this step, basic calculations are performed using the normal durations of activities to set up a CPM schedule. Once the scheduler inputs the necessary information identified in the first step, the model automatically calculates the project duration, start/finish times and floats of the activities in the project network. After the start/finish times and floats of all activities are determined, an initial CPM network can be plotted that displays both specific information for each activity and the critical path(s).

Step 3: In this step, two constraints are specified. The first constraint ensures that the crash duration of an activity cannot exceed the allowable crash duration determined for this activity. The allowable crash duration is equal to the maximum crash duration of the activity multiplied by crash duration consumption rate (Eq. 1). The crash duration consumption rate is the percentage that is set to determine the maximum amount of crash duration that an activity can consume with safety margin. The second constraint prevents 
violating the predecessor-successor relationships between activities by recalculating the start/finish times and floats of activities after each crashing step. By this way, shifting the normal durations of the crashed critical activities does not violate the precedence relationships in the network.

$$
a c t_{i}=m c t_{i} \times c r_{i}
$$

Step 4: In this step, the crashing process starts and the proposed model is applied to this process. First, critical path(s) on the project network are identified with basic CPM calculations using the normal durations of activities. Secondly, crashing alternatives are determined, which can shorten all critical paths for one day. These alternatives can consist of one critical activity or critical activities, especially if there is more than one critical path. Thirdly, an alternative with a minimum daily crashing cost is selected. The daily crashing cost of an activity $\left(C c_{i}\right)$ is calculated as a percentage $\left(P_{1} \%\right)$ of the daily normal cost of that activity $\left(d n c_{i}\right)$ calculated by dividing the normal cost of an activity $\left(n c_{i}\right)$ by its normal duration $\left(t_{i}\right)$ (Eq. 2-3). Fourthly, the normal duration of the critical activity or activities in the alternative is shortened for one day and basic CPM calculations are performed again on the project network. Thus, the project duration is shortened for one day and this process continues in the same way until one of the critical paths on the project network becomes uncompressible.

$$
\begin{aligned}
& d n c_{i}=\frac{n c_{i}}{t_{i}} \\
& c c_{i}=d n c_{i} \times P_{1}
\end{aligned}
$$

Step 5: In this step, some transitional outputs are computed, as the project duration is shortened day by day and the crashing process is repeated until a feasible solution cannot be found. The transitional outputs involve updated project duration, the number of activities in each crashing alternative, daily crashing cost of each crashing alternative (Eq. 4), the number of crashed days for each activity, total normal (direct) cost (Eq. 5), total indirect cost (Eq. 6), total crashing cost (Eq. 7) and total project cost (Eq. 8). The transitional outputs of the proposed model and their notations are presented in Table 2.

Table 2. The transitional outputs of the proposed model and their notations.

\begin{tabular}{ll}
\hline Notation & Definition \\
\hline$U P D$ & Updated project duration \\
$L$ & The number of activities in the crashing alternative $a$ \\
$c C_{a}$ & Daily crashing cost of crashing alternative $a$ \\
$x_{i}$ & The number of crashed days for activity $i$ \\
$T D C$ & Total normal (direct) cost \\
$T I C$ & Total indirect cost \\
$T C C$ & Total crashing cost \\
$T P C$ & Total project cost \\
\hline
\end{tabular}

The equations used to compute the transitional outputs are presented in Equations 4-7.

$$
\begin{aligned}
& c c_{a}=\sum_{i=1}^{L} c c_{i} \\
& T D C=\sum_{i=1}^{N} n c_{i} \\
& T I C=U P D \times i c_{p} \\
& T C C=\sum_{i=1}^{N} x_{i} \times c c_{i}
\end{aligned}
$$

Step 6: In this step, the objective function for project crashing process is determined. For this purpose, first the total project cost (Eq. 8) is calculated, which is the sum of total direct cost, total indirect cost and total crashing cost. 


$$
T P C=T D C+T I C+T C C
$$

The objective function ( $Z$ ) is the minimization of the total project cost (Eq. 9).

$$
Z=\min (T P C)
$$

Step 7: In this step, a Monte Carlo simulation is performed to see whether the proposed model is useful or not. In order to use in the Monte Carlo simulation, the optimistic and pessimistic durations of activities are calculated using their updated normal durations after completing the crashing process. Therefore, first, the normal durations of activities are updated. The updated normal durations of activities $\left(u t_{i}\right)$ are calculated by subtracting the crashed durations from their initial normal durations (Eq. 10). The optimistic durations of activities $\left(o t_{i}\right)$ are assumed to be equal to their updated normal durations (Eq. 11). The pessimistic durations of activities $\left(p t_{i}\right)$ are assumed to be $\left(P_{2} \%\right)$ higher than their updated normal durations (Eq. 12). However, if an activity is crashed, the pessimistic duration of that activity is also considered equal to the updated normal duration. In the model, the triangular distribution is used to generate random activity duration using the optimistic, updated normal and pessimistic durations of activities in each iteration. After the scheduler inputs the necessary duration information for the activities, the model automatically calculates and records the project duration for each iteration. As a result, the probability of the project's completion at the latest in crashed project duration is determined via the Monte Carlo simulation.

$$
\begin{aligned}
& u t_{i}=t_{i}-x_{i} \\
& o t_{i}=u t_{i} \\
& p t_{i}=u t_{i} \times\left(1+P_{2}\right)
\end{aligned}
$$

\section{Illustrative example}

A network consisting of 18 activities from the literature is used to demonstrate how the proposed model can be applied in a real-life project [18]. Some assumptions accepted before applying the proposed model to the illustrative example are as follows:

- Daily crashing costs of activities are accepted as $40 \%\left(P_{1}\right)$ of their daily normal (direct) costs.

- The daily indirect cost is determined as $\$ 100$.

- The optimistic durations of activities are assumed to be equal to their updated normal durations.

- The pessimistic durations of activities are assumed to be $5 \%\left(P_{2}\right)$ higher than their updated normal durations.

In addition, two limitations of the proposed model are as follows:

- The proposed model considers only the finish to start (FS) relationship, which is the traditional and most common dependency relationship between activities in the project network.

- The proposed model considers only "normal critical activity" out of the nine critical activity types defined theoretically by Hajdu et al. in 2016 [12] for use in the project crashing process.

The network of the illustrative example, which displays predecessor-successor relationships, normal durations (in days), early start/finish times $\left(E S_{i}, E F_{i}\right)$, late start/finish times $\left(L S_{i}, L F_{i}\right)$, and total floats $\left(T F_{i}\right)$ of the activities is presented in Figure 1. The inputs for the illustrative example is presented in Table 3. 


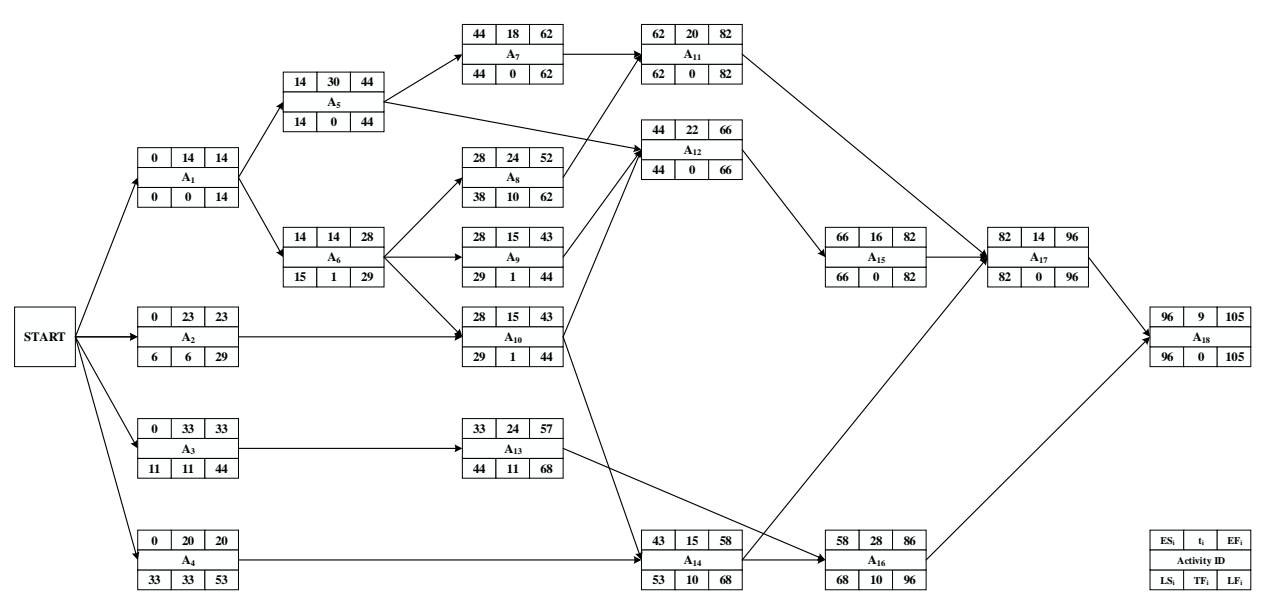

Fig. 1. Network for illustrative example.

Before running the project crashing model, the model asks for assigning a crash duration consumption rate to the activities. In project crashing model, the scheduler is allowed to assign crash duration consumption rate to each activity according to a preferred criterion. In this example, the maximum rate is set as $80 \%$ for the crash duration consumption of the activities that are scheduled to start before and on the $52^{\text {th }}$ day. In other words, setting a crash duration consumption of $80 \%$ implies that an activity that is scheduled to start in the first half of the project cannot consume more than $80 \%$ of its maximum crash duration in project crashing. On the other hand, a lower maximum crash duration consumption rate (i.e., 50\%) is assigned to the activities that are scheduled to start after the $52^{\text {th }}$ day. This crash duration consumption rate implies that an activity that is schedule to start in the second half of the project cannot consume more than $50 \%$ of its maximum crash duration in project crashing. The preferred trade-off strategy intends to provide more flexibility for the critical activities scheduled to be completed in the second half of the project to be recrashed if necessary. Providing this flexibility may help prevent severe delays in the project completion, which in turn improve the overall project performance.

Table 3. Inputs of the illustrative example.

\begin{tabular}{lllllllll}
\hline $\begin{array}{l}\text { Activity } \\
\text { ID }\end{array}$ & $\mathrm{IPA}^{*}$ & $\begin{array}{l}t_{i} \\
(\text { Day })\end{array}$ & $\begin{array}{l}m c t_{i} \\
(\text { Day })\end{array}$ & $c r_{i}$ & $\begin{array}{l}a c t_{i} \\
(\text { Day })\end{array}$ & $\begin{array}{l}n c_{i} \\
(\$)\end{array}$ & $\begin{array}{l}d n c_{i} \\
(\$ / \text { Day })\end{array}$ & $\begin{array}{l}c c_{i} \\
(\$ / \text { day })\end{array}$ \\
\hline $\mathrm{A}_{1}$ & Start & 14 & 4 & 0.8 & 3 & $3,500.00$ & 250.00 & 100.00 \\
$\mathrm{~A}_{2}$ & Start & 23 & 5 & 0.8 & 4 & $11,500.00$ & 500.00 & 200.00 \\
$\mathrm{~A}_{3}$ & Start & 33 & 8 & 0.8 & 6 & $8,250.00$ & 250.00 & 100.00 \\
$\mathrm{~A}_{4}$ & Start & 20 & 4 & 0.8 & 3 & $2,500.00$ & 125.00 & 50.00 \\
$\mathrm{~A}_{5}$ & $\mathrm{~A}_{1}$ & 30 & 6 & 0.8 & 4 & $3,000.00$ & 100.00 & 40.00 \\
$\mathrm{~A}_{6}$ & $\mathrm{~A}_{1}$ & 14 & 3 & 0.8 & 2 & $2,800.00$ & 200.00 & 80.00 \\
$\mathrm{~A}_{7}$ & $\mathrm{~A}_{5}$ & 18 & 6 & 0.8 & 4 & $1,800.00$ & 100.00 & 40.00 \\
$\mathrm{~A}_{8}$ & $\mathrm{~A}_{6}$ & 24 & 7 & 0.8 & 5 & $1,800.00$ & 75.00 & 30.00 \\
$\mathrm{~A}_{9}$ & $\mathrm{~A}_{6}$ & 15 & 3 & 0.8 & 2 & $2,625.00$ & 175.00 & 70.00 \\
$\mathrm{~A}_{10}$ & $\mathrm{~A}_{2}, \mathrm{~A}_{6}$ & 15 & 3 & 0.8 & 2 & 375.00 & 25.00 & 10.00 \\
$\mathrm{~A}_{11}$ & $\mathrm{~A}_{7}, \mathrm{~A}_{8}$ & 20 & 4 & 0.5 & 2 & $1,500.00$ & 75.00 & 30.00 \\
$\mathrm{~A}_{12}$ & $\mathrm{~A}_{5}, \mathrm{~A}_{9}, \mathrm{~A}_{10}$ & 22 & 5 & 0.8 & 4 & $2,750.00$ & 125.00 & 50.00 \\
$\mathrm{~A}_{13}$ & $\mathrm{~A}_{3}$ & 24 & 8 & 0.8 & 6 & $4,500.00$ & 187.50 & 75.00 \\
$\mathrm{~A}_{14}$ & $\mathrm{~A}_{4}, \mathrm{~A}_{10}$ & 15 & 5 & 0.8 & 4 & $4,500.00$ & 300.00 & 120.00 \\
$\mathrm{~A}_{15}$ & $\mathrm{~A}_{12}$ & 16 & 0 & 0.5 & 0 & $3,500.00$ & 218.75 & 87.50 \\
$\mathrm{~A}_{16}$ & $\mathrm{~A}_{13}, \mathrm{~A}_{14}$ & 28 & 8 & 0.5 & 4 & $5,250.00$ & 187.50 & 75.00 \\
$\mathrm{~A}_{17}$ & $\mathrm{~A}_{11}, \mathrm{~A}_{14}, \mathrm{~A}_{15}$ & 14 & 3 & 0.5 & 1 & $2,800.00$ & 200.00 & 80.00 \\
$\mathrm{~A}_{18}$ & $\mathrm{~A}_{16}, \mathrm{~A}_{17}$ & 9 & 2 & 0.5 & 1 & $2,025.00$ & 225.00 & 90.00 \\
\hline${ }^{*} \mathrm{IPA}: \mathrm{Imm} e d i a t e$ Predecessor Activity & & & & &
\end{tabular}

When the required information is inputted and the proposed model is run, first of all, early/late start times, early/late finish times, and total floats of the activities are calculated and the initial schedule plotted (Figure 1). The project duration is calculated to be 105 days. After plotting the initial schedule, critical activities are automatically identified by the proposed model. Then, the developed model automatically selects the crashing alternative, with the lowest daily crashing cost. In the developed model, the project duration is shortened day by day. The process is repeated until a feasible solution cannot be found. It should also be 
noted that in project crashing, each activity can be crashed as much as the allowable crash duration, not as much as the maximum crash duration.

In the proposed model, it is assumed that allowable crash durations of the activities are taken into account during the crashing process. After the implementation of this model, the findings concerning the updated project durations, the sequence of crashed activities, daily crashing costs, cumulative crashing costs, total normal cost, total indirect costs and cumulative total project costs are presented in Table 4.

Table 4. The findings obtained by applying the proposed crashing model to the illustrative example.

\begin{tabular}{|c|c|c|c|c|c|c|}
\hline $\begin{array}{l}\text { Project } \\
\text { Duration } \\
\text { (Day) }\end{array}$ & $\begin{array}{l}\text { Sequence of } \\
\text { Crashed } \\
\text { Activities }\end{array}$ & $\begin{array}{l}\text { Daily } \\
\text { Crashing } \\
\text { Cost } \\
\text { (\$/day) }\end{array}$ & $\begin{array}{l}\text { Cumulative } \\
\text { Crashing } \\
\text { Cost }(\$) \\
(1)\end{array}$ & $\begin{array}{l}\text { Total } \\
\text { Normal } \\
\text { Cost }(\$) \\
(2)\end{array}$ & $\begin{array}{l}\text { Total } \\
\text { Indirect } \\
\text { Cost }(\$) \\
(3)\end{array}$ & $\begin{array}{l}\text { Cumulative } \\
\text { Total Project } \\
\text { Cost }(\$) \\
(1+2+3)\end{array}$ \\
\hline 105 & - & 0.00 & 0.00 & $64,975.00$ & $10,500.00$ & $75,475.00$ \\
\hline 104 & $\mathrm{~A}_{5}$ & 40.00 & 40.00 & $64,975.00$ & $10,400.00$ & $75,415.00$ \\
\hline 103 & $A_{11}, A_{12}$ & 80.00 & 120.00 & $64,975.00$ & $10,300.00$ & $75,395.00$ \\
\hline 102 & $A_{11}, A_{12}$ & 80.00 & 200.00 & $64,975.00$ & $10,200.00$ & $75,375.00$ \\
\hline 101 & $A_{17}$ & 80.00 & 280.00 & $64,975.00$ & $10,100.00$ & $75,355.00$ \\
\hline 100 & $A_{7}, A_{12}$ & 90.00 & 370.00 & $64,975.00$ & $10,000.00$ & $75,345.00$ \\
\hline 99 & $A_{7}, A_{12}$ & 90.00 & 460.00 & $64,975.00$ & $9,900.00$ & $75,335.00$ \\
\hline 98 & $A_{18}$ & 90.00 & 550.00 & $64,975.00$ & $9,800.00$ & $75,325.00$ \\
\hline 97 & $A_{1}$ & 100.00 & 650.00 & $64,975.00$ & $9,700.00$ & $75,325.00$ \\
\hline 96 & $A_{1}$ & 100.00 & 750.00 & $64,975.00$ & $9,600.00$ & $75,325.00$ \\
\hline 95 & $A_{1}$ & 100.00 & 850.00 & $64,975.00$ & $9,500.00$ & $75,325.00$ \\
\hline 94 & $A_{5}, A_{9}, A_{10}$ & 120.00 & 970.00 & $64,975.00$ & $9,400.00$ & $75,345.00$ \\
\hline 93 & $A_{5}, A_{9}, A_{10}$ & 120.00 & $1,090.00$ & $64,975.00$ & $9,300.00$ & $75,365.00$ \\
\hline 92 & $A_{5}, A_{6}, A_{16}$ & 195.00 & $1,285.00$ & $64,975.00$ & $9,200.00$ & $75,460.00$ \\
\hline
\end{tabular}

The traditional project crashing model was also applied to the illustrative example. In the traditional model, it is assumed that allowable crash durations of the activities are not taken into account during the crashing process. After the implementation of this model, the findings concerning the updated project durations, the sequence of crashed activities, daily crashing costs, cumulative crashing costs, total normal cost, total indirect costs and cumulative total project costs are presented in Table 5.

Table 5. The findings obtained by applying the traditional crashing model to the illustrative example.

\begin{tabular}{lllllll}
\hline $\begin{array}{l}\text { Project } \\
\begin{array}{l}\text { Duration } \\
\text { (Day) }\end{array}\end{array}$ & $\begin{array}{l}\text { Sequence of } \\
\text { Crashed } \\
\text { Activities }\end{array}$ & $\begin{array}{l}\text { Daily } \\
\text { Crashing } \\
\text { Cost } \\
(\$ / \text { day })\end{array}$ & $\begin{array}{l}\text { Cumulative } \\
\text { Crashing } \\
\text { Cost }(\$) \\
(1)\end{array}$ & $\begin{array}{l}\text { Total } \\
\text { Normal } \\
\text { Cost }(\$) \\
(2)\end{array}$ & $\begin{array}{l}\text { Total } \\
\text { Indirect } \\
\text { Cost }(\$) \\
(3)\end{array}$ & $\begin{array}{l}\text { Cumulative } \\
\text { Total Project } \\
\text { Cost }(\$) \\
(1+2+3)\end{array}$ \\
\hline 105 & - & 0.00 & 0.00 & $64,975.00$ & $10,500.00$ & $75,475.00$ \\
104 & $\mathrm{~A}_{5}$ & 40.00 & 40.00 & $64,975.00$ & $10,400.00$ & $75,415.00$ \\
103 & $\mathrm{~A}_{11}, \mathrm{~A}_{12}$ & 80.00 & 120.00 & $64,975.00$ & $10,300.00$ & $75,395.00$ \\
102 & $\mathrm{~A}_{11}, \mathrm{~A}_{12}$ & 80.00 & 200.00 & $64,975.00$ & $10,200.00$ & $75,375.00$ \\
101 & $\mathrm{~A}_{11}, \mathrm{~A}_{12}$ & 80.00 & 280.00 & $64,975.00$ & $10,100.00$ & $75,355.00$ \\
100 & $\mathrm{~A}_{11}, \mathrm{~A}_{12}$ & 80.00 & 360.00 & $64,975.00$ & $10,000.00$ & $75,335.00$ \\
99 & $\mathrm{~A}_{17}$ & 80.00 & 440.00 & $64,975.00$ & $9,900.00$ & $75,315.00$ \\
98 & $\mathrm{~A}_{17}$ & 80.00 & 520.00 & $64,975.00$ & $9,800.00$ & $75,295.00$ \\
97 & $\mathrm{~A}_{17}$ & 80.00 & 600.00 & $64,975.00$ & $9,700.00$ & $75,275.00$ \\
\hline
\end{tabular}


Table 5 (cont'd). The findings obtained by applying the traditional crashing model to the illustrative example.

\begin{tabular}{|c|c|c|c|c|c|c|}
\hline $\begin{array}{l}\text { Project } \\
\text { Duration } \\
\text { (Day) }\end{array}$ & $\begin{array}{l}\text { Sequence of } \\
\text { Crashed } \\
\text { Activities }\end{array}$ & $\begin{array}{l}\text { Daily } \\
\text { Crashing } \\
\text { Cost } \\
(\$ / \text { day })\end{array}$ & $\begin{array}{l}\text { Cumulative } \\
\text { Crashing } \\
\text { Cost (\$) } \\
(1)\end{array}$ & $\begin{array}{l}\text { Total } \\
\text { Normal } \\
\text { Cost }(\$) \\
(2)\end{array}$ & $\begin{array}{l}\text { Total } \\
\text { Indirect } \\
\text { Cost }(\$) \\
(3)\end{array}$ & $\begin{array}{l}\text { Cumulative } \\
\text { Total Project } \\
\text { Cost }(\$) \\
(1+2+3)\end{array}$ \\
\hline 96 & $A_{7}, A_{12}$ & 90.00 & 690.00 & $64,975.00$ & $9,600.00$ & $75,265.00$ \\
\hline 95 & $\mathrm{~A}_{18}$ & 90.00 & 780.00 & $64,975.00$ & $9,500.00$ & $75,255.00$ \\
\hline 94 & $\mathrm{~A}_{18}$ & 90.00 & 870.00 & $64,975.00$ & $9,400.00$ & $75,245.00$ \\
\hline 93 & $A_{1}$ & 100.00 & 970.00 & $64,975.00$ & $9,300.00$ & $75,245.00$ \\
\hline 92 & $A_{1}$ & 100.00 & $1,070.00$ & $64,975.00$ & $9,200.00$ & $75,245.00$ \\
\hline 91 & $A_{1}, A_{13}$ & 175.00 & $1,245.00$ & $64,975.00$ & $9,100.00$ & $75,320.00$ \\
\hline 90 & $A_{1}, A_{13}$ & 175.00 & $1,420.00$ & $64,975.00$ & $9,000.00$ & $75,395.00$ \\
\hline 89 & $A_{5}, A_{9}, A_{10}, A_{13}$ & 195.00 & $1,615.00$ & $64,975.00$ & $8,900.00$ & $75,490.00$ \\
\hline 88 & $A_{5}, A_{9}, A_{10}, A_{13}$ & 195.00 & $1,810.00$ & $64,975.00$ & $8,800.00$ & $75,585.00$ \\
\hline 87 & $A_{5}, A_{9}, A_{10}, A_{13}$ & 195.00 & $2,005.00$ & $64,975.00$ & $8,700.00$ & $75,680.00$ \\
\hline 86 & $A_{5}, A_{6}, A_{13}$ & 195.00 & $2,200.00$ & $64,975.00$ & $8,600.00$ & $75,775.00$ \\
\hline 85 & $A_{2}, A_{5}, A_{6}, A_{13}$ & 395.00 & $2,495.00$ & $64,975.00$ & $8,500.00$ & $76,070.00$ \\
\hline
\end{tabular}

After the project crashing process is completed, the findings obtained by the proposed model are compared with those obtained by the traditional model. The relationship between the project duration and the total project cost after the implementation of these models is presented in Table 6.

Table 6. Comparison of the two models in terms of total project cost and project duration.

\begin{tabular}{lll}
\hline Project Duration (Day) & The Traditional Model & The Proposed Model \\
\hline 105 & $75,475.00$ & $75,475.00$ \\
95 & $75,255.00$ & $75,325.00$ \\
92 & $75,245.00$ & $75,460.00$ \\
85 & $76,070.00$ & - \\
\hline
\end{tabular}

Based on Table 6, the following results can be interpreted:

- In the initial schedule, the project duration is 105 days and the total project cost is $\$ 75,475.00$.

- In the proposed model, the minimum duration that the project can be crashed is 92 days and the corresponding total project cost is $\$ 75,460.00$.

- In the proposed model, the minimum total project cost is $\$ 75,325.00$, and the corresponding project duration is 95 days.

- In the traditional model, the minimum duration that the project can be crashed is 85 days and the corresponding total project cost is $\$ 76,070.00$.

- In the traditional model, the minimum total project cost is $\$ 75,245.00$, and the corresponding project duration is 92 days.

Once the project crashing process is completed, a Monte Carlo simulation is carried out to prove that the proposed model is useful. First, normal durations of the activities are updated. Then, the optimistic and pessimistic durations of activities are calculated using their updated normal durations. For the Monte Carlo simulation, the number of iterations to be applied is specified as 1000, and the triangular distribution is used to generate random activity duration using the optimistic, updated normal and pessimistic durations of activities in each iteration. After the scheduler inputs the necessary duration information for the activities, the model automatically calculates and records the project duration for each iteration. As a result, the probability of completion of the project at the latest in crashed project duration is determined via the Monte Carlo simulation. This process is applied similarly in both the proposed model and the traditional model to make comparison. In the proposed model, as the minimum duration that the project can be crashed is the $92^{\text {nd }}$ day, the $92^{\text {nd }}$ day of the project is determined as a reference point for the comparison 
to be meaningful and interpretable. As a result of the Monte Carlo simulation, the project completion durations and the frequency values of these durations according to both models are presented in Figure 2 .

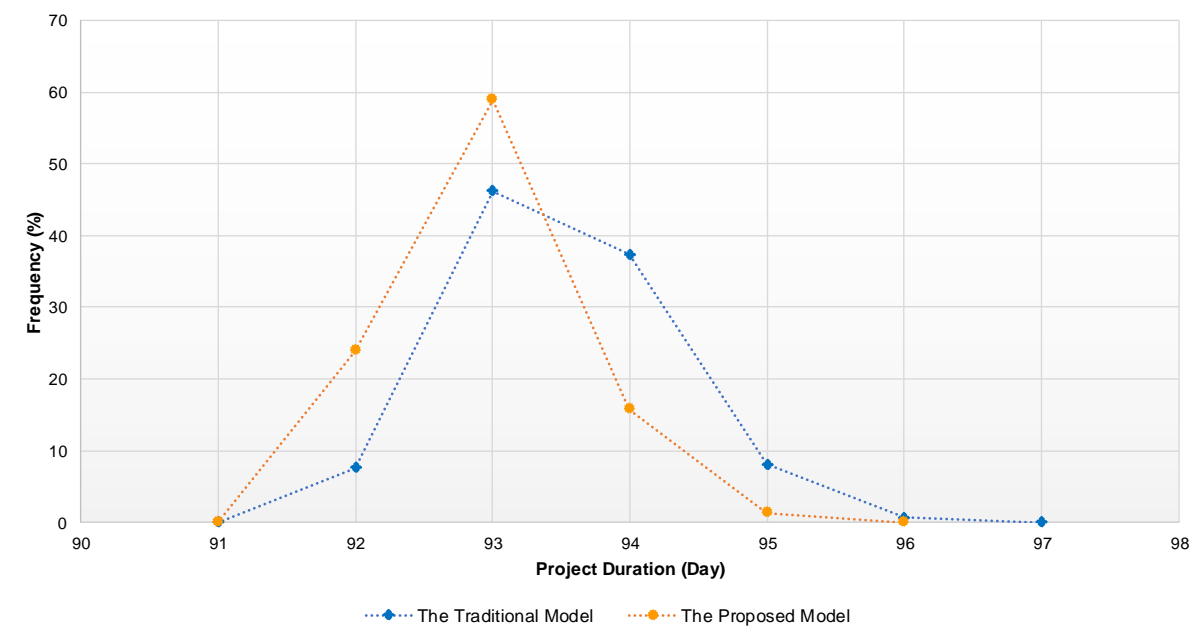

Fig. 2. Comparison of the two models in terms of project durations and their frequency values.

Based on Figure 2, the following results can be interpreted:

- In the proposed model, the probability of completing the project at the latest in $92^{\text {nd }}$ day is $24.00 \%$.

- In the proposed model, the probability of completing the project at the latest in $95^{\text {th }}$ day is $100.00 \%$.

- In the traditional model, the probability of completing the project at the latest in $92^{\text {nd }}$ day is $7.60 \%$.

- In the traditional model, the probability of completing the project at the latest in $95^{\text {th }}$ day is $97.30 \%$.

As a summary, shorter project duration and lower total project costs are achieved in the traditional model compared to the proposed model for project crashing (see Table 6). The main reason for this finding is that in the proposed model, each activity can be crashed as much as the allowable crash duration, not as much as the maximum crash duration. However, it should be noted that the proposed model provides flexibility for schedulers to avoid delays during execution phase of the project through this trade-off strategy. Therefore, the difference between the total project costs of the two models on the same project day can be considered as "a cost of flexibility" for the future of the project. Furthermore, when the findings of the Monte Carlo simulation applied after project crashing are carefully examined, it can be seen that the proposed model offers a better distribution than the traditional model for the possibility of the project completion durations and the frequency values associated with these durations (see Figure 2). For example, on $92^{\text {nd }}$ day of the project, although the proposed model in terms of total project costs is $\$ 215$ more than the traditional model, the probability of completion of the project on the same day in the proposed model is $16.40 \%$ higher than the traditional model (see Table 6 and Figure 2). As a result, in the light of the findings of this study, the proposed model has proven to be a useful tool for use in project crashing problems.

\section{Conclusion}

Project crashing is an advanced project management strategy that refers to a particular type of project schedule compression and it is an important topic that has attracted the attention of numerous researchers for many years. In most of these studies, crash duration consumption rates of activities are neglected. This study proposes a model, which considers crash duration consumption rates of activities, for solving the project crashing problem. For this purpose, the proposed model was developed through Visual Basic Programming Language integrated with Microsoft (MS) Excel. The applicability of the proposed model is presented along with an illustrative example. In addition, the traditional project crashing model was also applied to the illustrative example. Once the project crashing process is completed, the findings obtained by the proposed model are compared with those obtained by the traditional model. As a result, shorter project duration and lower total project costs are achieved in the traditional model compared to the proposed model for project crashing. The main reason for this finding is that in the proposed model, each activity can be crashed as much as the allowable crash duration, not as much as the maximum crash 
duration. On the other hand, the findings of the Monte Carlo simulation applied after project crashing revealed that the proposed model offers a better distribution than the traditional model for the possibility of the project completion durations and the frequency values associated with these durations. In sum, while the proposed model maintains schedule flexibility, it minimizes the likelihood of severe delays. The findings of this study indicated that the proposed model is a useful tool to be used in project crashing problems. In addition, the proposed model can be used in crashing any construction project as well as non-construction projects. This study has some limitations. First, different findings may be obtained by applying the proposed model to different cases or by assigning crash duration consumption rates based on a different strategy for activities in the same problem. Second, the assessment of different dependency relationships between activities (i.e., start to start, start to finish, finish to finish) and different critical activity types can be addressed in future studies that will focus on project crashing problems.

\section{References}

[1] Arditi, D., Nayak, S., Damci, A. Effect of organizational culture on delay in construction. International Journal of Project Management, 35(2), 136-147. (2017). https://doi.org/10.1016/j.ijproman.2016.10.018

[2] Kumar, D. Causes and Effects of Delays in Indian Construction Projects. International Research Journal of Engineering and Technology, 3(4), 1831-1837. (2016). e-ISSN: 2395 -0056. https://www.irjet.net/archives/V3/i4/IRJET-V3I4363.pdf

[3] Leon, H., Osman, H., Georgy, M., Elsaid, M. System dynamics approach for forecasting performance of construction projects. Journal of Management in Engineering, 34(1), 04017049. (2018). https://doi.org/10.1061/(ASCE)ME.1943-5479.0000575

[4] Enshassi, A., Mohamed, S., Abushaban, S. Factors affecting the performance of construction projects in the Gaza strip. Journal of Civil engineering and Management, 15(3), 269-280. (2009). https://doi.org/10.3846/1392-3730.2009.15.269-280

[5] Göçken, T. Solution of fuzzy multi-objective project crashing problem. Neural Computing and Applications, 23(7-8), 2167-2175. (2013). https://doi.org/10.1007/s00521-012-1167-z

[6] Ballesteros-Perez, P., Elamrousy, K. M., González-Cruz, M. C. Non-linear time-cost trade-off models of activity crashing: Application to construction scheduling and project compression with fast-tracking. Automation in Construction, 97, 229-240. (2019). https://doi.org/10.1016/j.autcon.2018.11.001

[7] Diaby, M., Cruz, J. M., Nsakanda, A. L. Project crashing in the presence of general non-linear activity time reduction costs. International Journal of Operational Research, 12(3), 318-332. (2011). https://doi.org/10.1504/IJOR.2011.042919

[8] Göçken, T., Baykasoğlu, A. Direct Solution of Time-Cost Tradeoff Problem with Fuzzy Decision Variables. Cybernetics and Systems, 47(3), 206-219. (2016). https://doi.org/10.1080/01969722.2016.1156913

[9] Mahmoudi, A., Feylizadeh, M. A mathematical model for crashing projects by considering time, cost, quality and risk. Journal of Project Management, 2(1), 27-36. (2017). https://doi.org/10.5267/j.jpm.2017.5.002

[10] Haque, K. M., Hasin, M., Akhtar, A. Genetic algorithm for project time-cost optimization in fuzzy environment. Journal of Industrial Engineering and Management (JIEM), 5(2), 364-381. (2012). https://doi.org/10.3926/jiem.410

[11] Hoang, N. D. NIDE: a novel improved differential evolution for construction project crashing optimization. Journal of Construction Engineering, 2014. (2014). https://doi.org/10.1155/2014/136397

[12] Hajdu, M., Skibniewski, M. J., Vanhoucke, M., Horvath, A., Brilakis, I. How Many Types of Critical Activities Exist? A Conjecture in Need of Proof. Procedia Engineering, 164, 3-11. (2016). https://doi.org/10.1016/j.proeng.2016.11.585

[13] Feylizadeh, M. R., Mahmoudi, A., Bagherpour, M., Li, D. F. Project crashing using a fuzzy multi-objective model considering time, cost, quality and risk under fast tracking technique: A case study. Journal of Intelligent \& Fuzzy Systems, 35(3), 3615-3631. (2018). https://doi.org/10.3233/JIFS-18171

[14] Kelley Jr, J. E., Walker, M. R. Critical-path planning and scheduling. In Papers presented at the December 1-3, 1959, eastern joint IRE-AIEE-ACM computer conference (pp. 160-173). (1959). https://doi.org/10.1145/1460299.1460318

[15] Hajdu, M., Isaac, S. Sixty years of project planning: history and future. Organization, Technology and Management in Construction: an International Journal, 8(1), 1499-1510. (2016). https://doi.org/10.1515/otmcj-2016-0013

[16] Rabie, M., El-Sayegh, S. Modelling of tri-parameter bidding integrating cost, time and risk: a stochastic approach. Journal of Financial Management of Property and Construction. 22(2), pp.117-134. (2017). https://doi.org/10.1108/JFMPC-06-2016-0024

[17] El-Sayegh, S.M., Al-Haj, R. A new framework for time-cost trade-off considering float loss impact. Journal of Financial Management of Property and Construction. 22(1), pp. 20-36. 2017. https://doi.org/10.1108/JFMPC-02-2016-0007

[18] Feng, C. W., Liu, L., Burns, S. A. Using genetic algorithms to solve construction time-cost trade-off problems. Journal of computing in civil engineering, 11(3), 184-189. (1997). https://doi.org/10.1061/(ASCE)0887-3801(1997)11:3(184) 